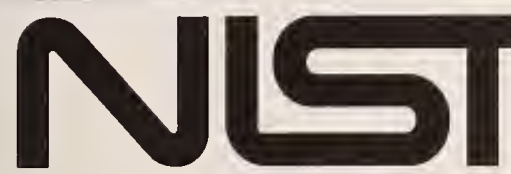

United States Department of Commerce Technology Administration

National Institute of Standards and Technology

NIST Technical Note 1418

Probabilistic Estimates of Design Load Factors for Wind-Sensitive Structures Using the "Peaks Over Threshold"' Approach

Timothy M. Whalen

$Q C$

100

.05753

N0.1418

1996 

in the development of technology ... needed to improve product quality, to modernize manufacturing processes, to ensure product reliability ... and to facilitate rapid commercialization ... of products based on new scientific discoveries."

NIST, originally founded as the National Bureau of Standards in 1901, works to strengthen U.S. industry's competitiveness; advance science and engineering; and improve public health, safety, and the environment. One of the agency's basic functions is to develop, maintain, and retain custody of the national standards of measurement, and provide the means and methods for comparing standards used in science, engineering, manufacturing, commerce, industry, and education with the standards adopted or recognized by the Federal Government.

As an agency of the U.S. Commerce Department's Technology Administration, NIST conducts basic and applied research in the physical sciences and engineering, and develops measurement techniques, test methods, standards, and related services. The Institute does generic and precompetitive work on new and advanced technologies. NIST's research facilities are located at Gaithersburg, MD 20899, and at Boulder, CO 80303. Major technical operating units and their principal activities are listed below. For more information contact the Public Inquiries Desk, 301-975-3058.

\section{Office of the Director}

- Advanced Technology Program

- Quality Programs

- International and Academic Affairs

\section{Technology Services}

- Manufacturing Extension Partnership

- Standards Services

- Technology Commercialization

- Measurement Services

- Technology Evaluation and Assessment

- Information Services

\section{Materials Science and Engineering}

Laboratory

- Intelligent Processing of Materials

- Ceramics

- Materials Reliability ${ }^{1}$

- Polymers

- Metallurgy

- Reactor Radiation

\section{Chemical Science and Technology}

Laboratory

- Biotechnology

- Chemical Kinetics and Thermodynamics

- Analytical Chemical Research

- Process Measurements

- Surface and Microanalysis Science

- Thermophysics ${ }^{2}$

\section{Physics Laboratory}

- Electron and Optical Physics

- Atomic Physics

- Molecular Physics

- Radiometric Physics

- Quantum Metrology

- Ionizing Radiation

- Time and Frequency

- Quantum Physics'
Manufacturing Engineering Laboratory

- Precision Engineering

- Automated Production Technology

- Intelligent Systems

- Manufacturing Systems Integration

- Fabrication Technology

\section{Electronics and Electrical Engineering}

Laboratory

- Microelectronics

- Law Enforcement Standards

- Electricity

- Semiconductor Electronics

- Electromagnetic Fields ${ }^{1}$

- Electromagnetic Technology ${ }^{1}$

- Optoelectronics ${ }^{1}$

Building and Fire Research Laboratory

- Structures

- Building Materials

- Building Environment

- Fire Safety

- Fire Science

\section{Computer Systems Laboratory}

- Office of Enterprise Integration

- Information Systems Engineering

- Systems and Software Technology

- Computer Security

- Systems and Network Architecture

- Advanced Systems

\section{Computing and Applied Mathematics}

Laboratory

- Applied and Computational Mathematics ${ }^{2}$

- Statistical Engineering ${ }^{2}$

- Scientific Computing Environments ${ }^{2}$

- Computer Scrvices

- Computer Systems and Communications ${ }^{2}$

- Information Systems 


\section{NIST Technical Note 1418}

\section{Probabilistic Estimates of Design Load Factors for Wind-Sensitive Structures Using the "Peaks Over Threshold"' Approach}

Timothy M. Whalen

Building and Fire Research Laboratory

National Institute of Standards and Technology

Gaithersburg, MD 20899-0001

April 1996

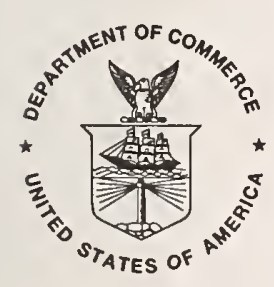

U.S. Department of Commerce

Michael Kantor, Secretary

Technology Administration

Mary L. Good, Under Secretary for Technology

National Institute of Standards and Technology

Arati Prabhakar, Director 
National Institute of Standards and Technology

Technical Note 1418

Natl. Inst. Stand. Technol.

Tech. Note 1418

30 pages (April 1996)

CODEN: NTNOEF
U.S. Government Printing Office

Washington: 1996

For sale by the Superintendent of Documents

U.S. Government Printing Office Washington, DC 20402 


\title{
Probabilistic Estimates of Design Load Factors for Wind-Sensitive Structures Using the "Peaks Over Threshold" Approach
}

\author{
Timothy M. Whalen \\ Building and Fire Research Laboratory \\ National Institute of Standards and Technology \\ Bldg. 226, Room B158 \\ Gaithersburg, MD 20899-0001
}

April 26, 1996

\begin{abstract}
The "peaks over threshold" method is used to estimate ratios of wind-induced loads with various long mean recurrence intervals to loads with a 50-year mean recurrence interval. The results support the conclusion that the load factor value of 1.3 specified in the ASCE Standards 7-93 and 7-95 is adequate for extratropical storm regions. However, for hurricane-prone regions, the results imply that the standard value of the load factor (even after being augmented by an importance factor specified in the standards) leads to nominal ultimate wind loads with considerably shorter mean recurrence intervals than is the case for extratropical regions. This suggests that the 1.3 load factor value specified in the ASCE Standards 7-93 and 7-95 is inadequate for wind-sensitive structures in hurricane-prone regions.
\end{abstract}

Key Words: building (codes); building technology; climatology; extreme value theory; hurricanes; load factors; structural engineering; structural reliability; threshold methods; wind (meteorology) 


\section{Introduction}

The nominal design wind load is an extreme load with a specified probability of being exceeded during a specified time interval. For codes and standards in the United States, this interval is usually 50 years, and the specified load is based upon a 50 -year nominal design wind speed. For example, for the inland Miami, Florida area, the ASCE Standard $7-93$ [1] and 7-95 [2] specify a nominal 50-year load based on a nominal 50-year design wind speed of $49.17 \mathrm{~m} / \mathrm{s}(110 \mathrm{mi} / \mathrm{h})$. It is expected, however, that a structure or element thereof should withstand wind loads substantially in excess of the 50-year wind load without loss of integrity. The wind load beyond which loss of integrity can be expected is referred to as the ultimate wind load. The ultimate strength provided for in the design of a structure is based upon an assumed nominal ultimate wind load equal to the nominal design wind load times a wind load factor.

The wind load factor should be selected so that the probability of occurence of the ultimate wind load is acceptably small. This probabilistic concept is important from an economic or insurance point of view. To the extent that evacuation or similar measures cannot be expected to prevent loss of life, it is important also from a safety point of view. However, attempts to estimate wind load factors on a probabilistic basis have so far not been successful. This may be due at least in part to the common use in reliability calculations of the assumption that wind speeds are modeled by probability distributions with infinite upper tails, e.g., Gumbel or Weibull distributions. In [3] and [12], it was assumed that the probability distribution of hurricane wind speeds is Weibull. However, the Weibull distribution is an asymptotic model for the distribution of the smallest extremes. For extreme largest values, the appropriate asymptotic model is either Gumbel, Fréchet, or reverse Weibull [4, 9]. As for the Gumbel distribution, it was found in [6] to yield what appeared to be unrealistically high ultimate wind loads.

Recent studies $[9,10]$ have produced evidence in support of the assumption that extreme wind speeds are modelled by the reverse Weibull distribution, which is tail-limited (i.e., has a finite-length upper tail). The purpose of this report is to explore the potential offered by this finding for estimating wind load factors on a probabilistic basis. This is done separately for hurricane winds (sec. 2) and for winds in extratropical regions (sec. 3). In this work, wind directionality effects are not taken into account. It is also assumed that the dominant load is due to wind. Our results are therefore applicable to wind-sensitive structures for which wind directionality effects are not significant. (Refer to [8] for a discussion of directionality effects.)

\section{Load Factors for Hurricane-Prone Regions}

In this section, we are interested in the estimation of wind load factors for those portions of the United States that have hurricanes and tropical storms as their most likely source of extreme winds. This region encompasses the coastal regions of the Gulf of Mexico and the Atlantic Ocean (see Fig. 1). Data for this study were obtained via simulation of hurricane winds based upon censored probabilistic models of the climatological parameters that influence hurricane structure. Consult [3] for a more complete discussion of the model. Censoring 


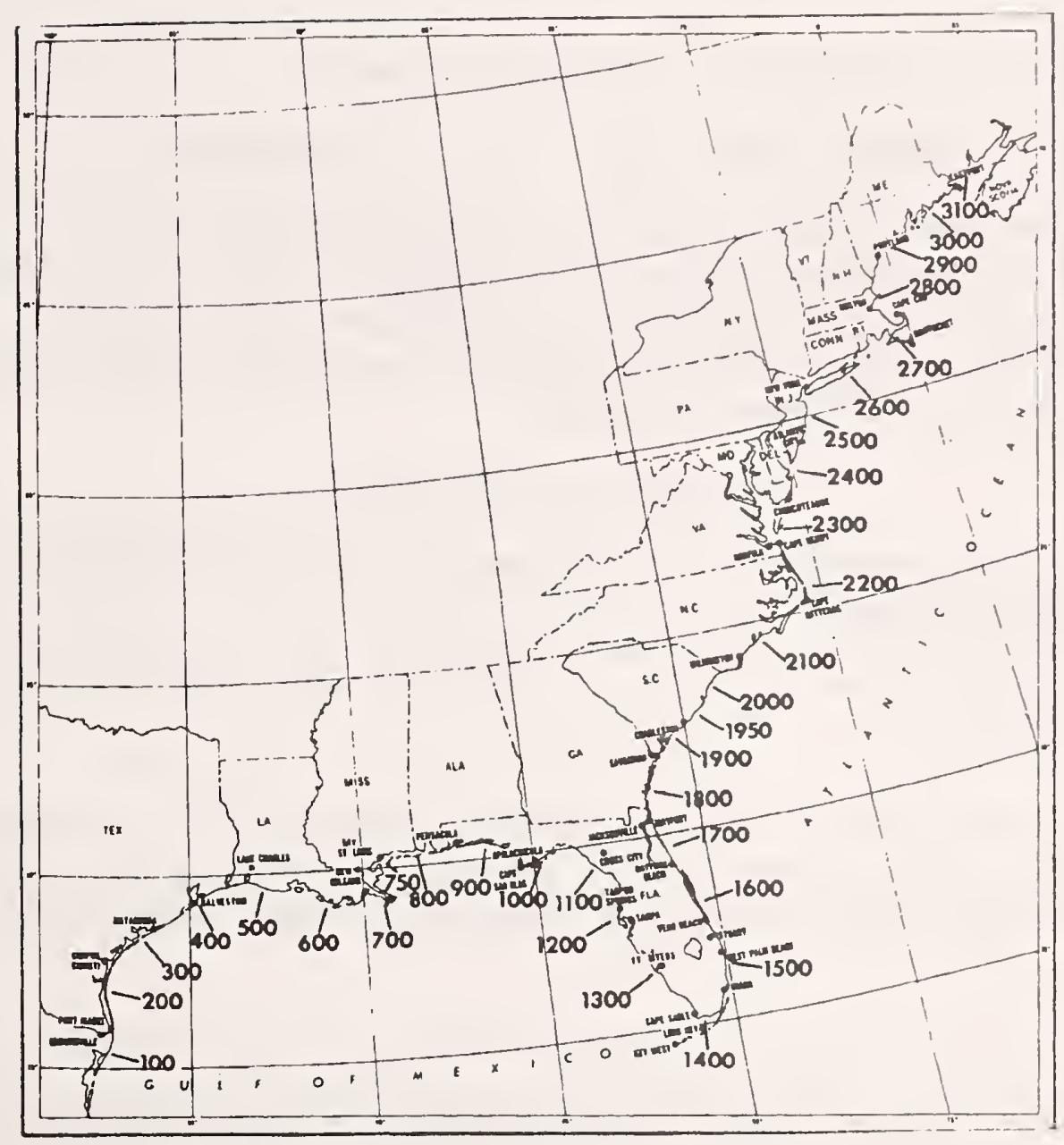

Figure 1: Locator map for the hurricane-prone region of the United States (from [11]).

was based on physical considerations and is in principle consistent with a tail-limited probabilistic model of extreme wind speeds. The data represent fastest one-minute hurricane speeds in knots at $10 \mathrm{~m}$ above ground over open terrain at the coastline at 55 equidistant locations. Data are available as maximum wind speeds within each of 16 half octants for each of 999 simulated hurricane events. As indicated earlier, we analyzed datasets consisting of the largest speed in each hurricane event regardless of direction. The estimated mean annual rate of occurence of hurricanes at each location is also included in the dataset. The data are available on tape and via anonymous file transfer. ${ }^{1}$

Analysis of the data was performed via programs that implement the de Haan version of the "peaks over threshold" method for estimating extreme value distribution parameters. ${ }^{2}$ A discussion of this method may be found in [5]. From the estimated distribution parameters, we obtained estimates of wind speeds having specified mean recurrence intervals $R$. (The recurrence interval $R$ in years is the inverse of the probability that that wind speed will be exceeded in any one year.) Under the assumption that a reverse Weibull distribution is valid,

\footnotetext{
${ }^{1}$ See [10] for details on obtaining the data.

${ }^{2}$ These programs are also availablc via anonymous file transfer; see the previous footnote.
} 
the probability of no exceedance of a given threshold speed is

$$
G(y)=\operatorname{Prob}[Y \leq y]=1-\left\{[1+(c y / a)]^{-1 / c}\right\},
$$

where $a$ and $c$ are location and tail-length parameters, respectively, $a>0, c<0, c y>-a$, $Y=X-u, X$ is the windspeed, and $u<X$ is a threshold assumed to be sufficiently high [9]. (More precisely, this is the conditional probability, given that $X>u$ for $u$ sufficiently large.) To obtain the estimate of the wind speed, let $\lambda$ represent the mean crossing rate of the threshold $u$ per year. Therefore, we can take

$$
\operatorname{Prob}[Y \leq y]=1-1 /(\lambda R)
$$

as an estimate of the probability of no exceedances. Equating these two probability expressions and solving for $y$ gives

$$
y=-a\left[1-(\lambda R)^{c}\right] / c,
$$

which in turn yields

$$
X_{R}=y+u
$$

as the estimated wind speed having a mean recurrence interval of $R$ for the threshold $u$. The wind speed with an infinite mean recurrence interval, i.e., the limiting upper wind speed as defined by the reverse Weibull distribution, is denoted by $X_{\text {inf }}$. Using eq (1) and setting $G(y)=1$, we can solve for $y$ and thus obtain

$$
X_{\text {inf }}=u-a / c .
$$

The wind load factor specified in the ASCE Standard 7-93 represents the ratio of the ultimate wind load to the wind load based upon the 50 -year nominal hurricane wind speed $X_{50}$ times a hurricane importance factor $F$. Since wind loads are proportional to the square of the wind speed, we form an estimate of the wind load factor $L_{R}$ according to:

$$
L_{R}=\left[X_{R} /\left(F * X_{50}\right)\right]^{2} \text {. }
$$

As specified on page 152 in the Commentary on ASCE Standard 7-95 [2], $F=1.05 . L_{\text {inf }}$ is defined by eq (6) with $X_{\text {inf }}$ replacing $X_{R}$.

We show representative plots of the estimated wind speeds $X_{R}$ and estimated wind load factors $L_{R}$ for various values of $R$ in Figure 2 for simulated hurricanes at Milepost 300 (a location near Matagorda Bay, Texas). ${ }^{3}$ Both the wind speeds $X_{R}$ and wind load factors $L_{R}$ display a great deal of variability for low thresholds $(u<25 \mathrm{~m} / \mathrm{s}$, roughly speaking). We note that inherent in the reverse Weibull model is the assumption that the thresholds $u$ correspond to high extreme wind speeds, and violations of this assumption may lead to poor distribution parameter estimates. Also, both $X_{R}$ and $L_{R}$ display variability for very high thresholds $(u>43 \mathrm{~m} / \mathrm{s}$, approximately). This is due to the relatively small sizes (fewer than 30 data points) of the wind speed data samples exceeding these thresholds. Between these two bounding cases, the values of $X_{R}$ and $L_{R}$ are fairly constant, although some fluctuation clearly exists.

\footnotetext{
${ }^{3}$ In all figures in this report, wind speeds are fastest-minute wind speeds at $10 \mathrm{~m}$ above ground over open terrain in meters per second.
} 


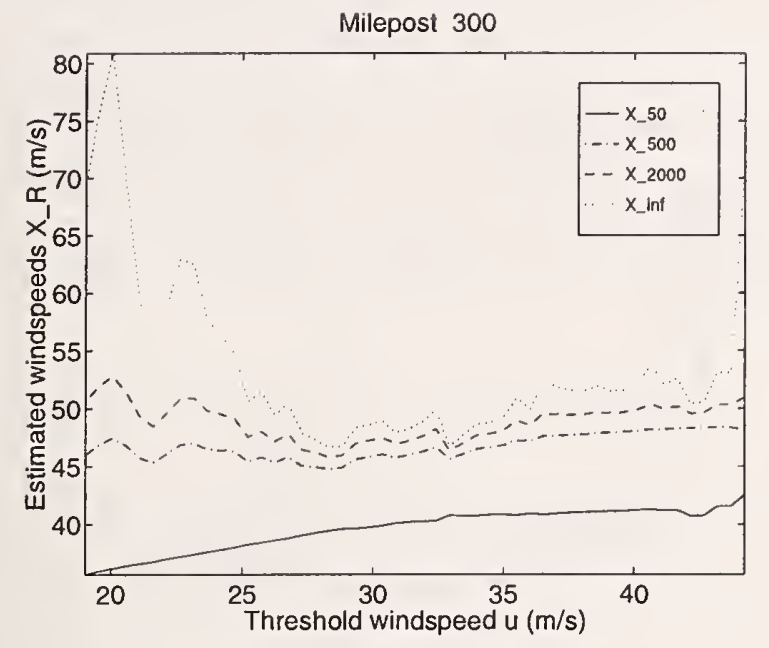

$X_{R}$ versus $u$.

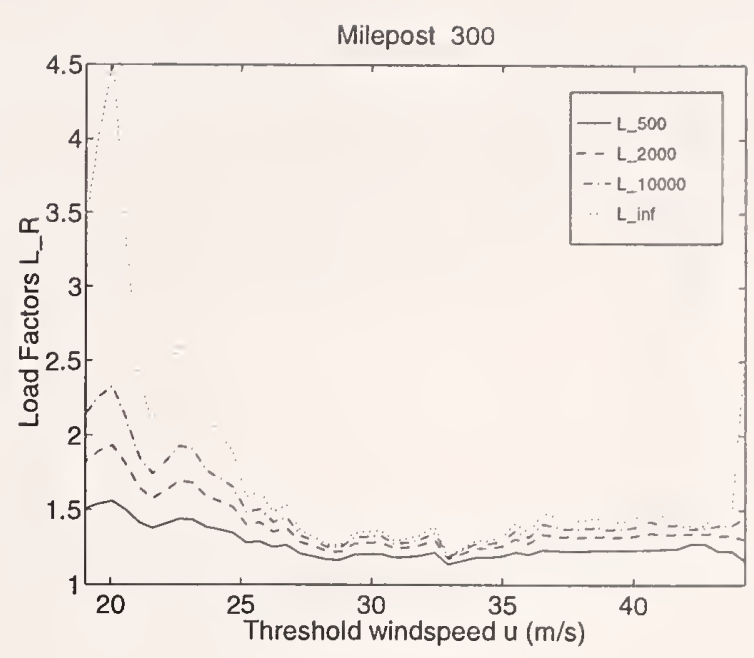

$L_{R}$ versus $u$.

Figure 2: Representative plots of estimated wind speeds $X_{R}$ and load factors $L_{R}$ versus threshold speed $u$.

Graphs of estimated wind load factors versus threshold speed for various locations along the Gulf of Mexico and Atlantic Ocean coastline are provided in Appendix A. Due to the previously mentioned reasons, no results have been shown for thresholds having more than 300 exceedances or fewer than 30 exceedances. Also, estimated load factors larger than 2.5 are not shown. For comparison, we have included in these plots a dotted line at $L_{R}=1.3$, representing the ASCE Standard 7-93 value of the wind load factor.

The graphs of Appendix A show noticeable variability in the load factors as a function of threshold, especially for the high recurrence intervals $R=10,000$ years and $R=\infty$. However, certain trends are discernable. For example, the load factor $L_{500}$, shown as a solid line in the graphs, is close to or higher than the design standard value of 1.3 for most mileposts. This result is in keeping with the conclusions of [10], which found that the load factor standard value corresponded to winds with relatively short mean recurrence intervals. This implies that the probability of exceedance of the nominal ultimate wind load (calculated in accordance with the standard) is about 0.002 (or larger) per year or, assuming that the design lifetime of the structure is 50 years, is equal to (or larger than) about

$$
1-(1-0.002)^{50}=0.095
$$

during the structure's lifetime.

\section{Load Factors for Extratropical Regions}

We now turn our attention to the estimation of wind load factors for areas of the United States in which tropical storms are not expected to occur. We use as our source of data 


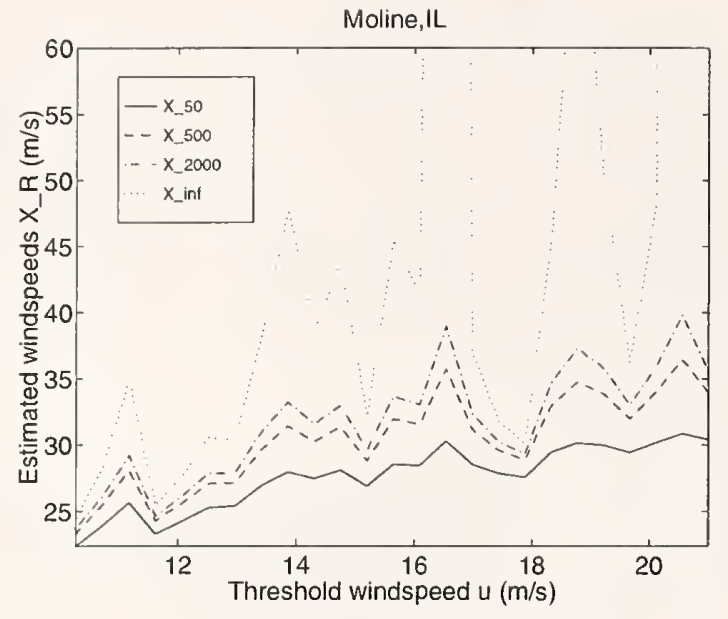

$X_{R}$ versus $u$.

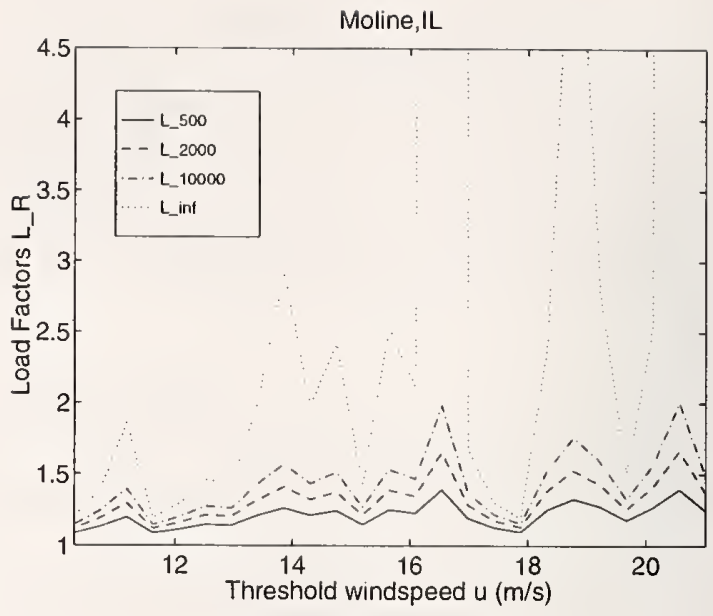

$L_{R}$ versus $u$.

Figure 3: Representative plots of estimated wind speeds $X_{R}$ and load factors $L_{R}$ versus threshold speed $u$.

the records of the largest daily wind speeds collected at 44 U.S. weather stations that lie outside of the area described in sec. 2. Each set contains approximately 20 years worth of daily fastest mile wind data. We once again used the de Haan estimation method, and the analysis proceeded largely as described in the previous section, with one additional step. ${ }^{4}$ In order to reduce possible correlations among the data due to a single storm producing strong winds for more than 1 day, the records were broken into intervals of 8 days, and maximum speeds in each interval were identified. If maxima of adjacent intervals (denoted by $I_{1}$ and $I_{2}$ ) were found to be less than 4 days apart, the following procedure was used. Let $I_{1}$ contain the smaller of the two maxima. This maximum was replaced by the highest value in $I_{1}$ separated from the maximum in $I_{2}$ by 4 days or more. This procedure insured that all data in the set were at least 4 days apart. The interval of 4 days was chosen because it represents a reasonable maximum duration of a strong wind storm. Analyses with interval lengths of 4 days and correlation periods of 2 days were performed and were found to produce no significant differences in the results. Previous studies [9] have shown that this procedure, while reducing the total number of data points used in the estimation process, tends to remove low wind speeds from consideration, resulting in a data set more representative of extreme winds.

In Figure 3, we show representative plots of the estimated wind speeds $X_{R}$ and wind load factors $L_{R}$ for data from Moline, IL, for which 15 years of daily wind speed data are available. Note that $L_{R}$ is still defined by eq (6) for extratropical regions, but the hurricane importance factor $F$ is now set to 1.00. As was true for the hurricanes, we note a downward trend for the estimated variates with lower thresholds. We ascribe this trend to bias associated with

\footnotetext{
${ }^{4}$ Again, both the data sets and analysis programs are available. See [9] for further information.
} 
the inclusion of relatively weak winds. For this reason, and to reduce sampling errors due to small sample sizes due to very high thresholds, we have plotted in Appendix B results only for thresholds having between 30 and 450 data points. Once again, we note that there is significant variability both among the plots and within a given plot. We may, however, state unequivocally that the load factor $L_{500}$ is considerably lower than was the case for hurricane winds for the majority of the stations. A comparison of the graphs of Appendix A and Appendix B also suggests that the tails of the load factor distributions are considerably shorter for stations in extratropical regions than in hurricane-prone stations.

\section{Discussion of Results}

Questions may arise as to whether our analyses of the hurricane wind speed data are affected significantly by the model used in the simulation that yielded the data. However, we note that the models upon which our data sets were based are considered reasonable for professional practice and that these data were used for the development of the ASCE Standard 7-93 wind speed map. Our analyses are therefore consistent with that wind speed map. The wind speed map of the ASCE Standard 7-95 differs from that of the ASCE Standard 7-93 in that (i) it uses peak gusts instead of fastest mile wind speeds (a difference of presentation rather than substance), and (ii) it uses a boundary layer model based on the Shapiro approximation [7] rather than an empirical boundary layer model. As was pointed out by Shapiro, this model does not describe the boundary layer structure in detail, especially near the eye wall of the hurricane where wind speeds are expected to be largest. Also, according to Shapiro, since this approximation entails a truncated spectral representation for the wind velocity, the resulting estimates can have errors of as much as $25 \%$. For this reason it is not clear that simulations based upon Shapiro's approximation are necessarily an improvement over earlier simulations. Given the present state of the art, it is our opinion that our results have an acceptable basis as far as the quality of the data is concerned. Nevertheless, we point out that the high degree of fluctuation in the estimates is a difficulty in the study of probabilistically determined wind load factors. This suggests the need for further improvements in both the quantity and quality of the data used in the estimation process and further study of probabilistic estimation techniques.

Finally, we recall that all of our results are applicable to wind-sensitive structures for which wind directionality effects are not significant. This is true for both hurricane-prone regions and regions not subject to hurricanes. An assessment of relative values of load factors in these two regions thus has a consistent basis.

\section{Conclusions}

In this report, we have used the "peaks over threshold" method to estimate ratios of wind-induced loads with various long mean recurrence intervals to loads with a 50-year mean recurrence interval. According to our estimates, the load factor value of 1.3 specified in the ASCE Standards 7-93 and 7-95 is adequate for extratropical storm regions; that is, it corresponds to nominal ultimate wind loads judged to have sufficiently long mean recurrence 
intervals. However, in hurricane-prone regions, the 1.3 standard value of the load factor (even after being augmented by an importance factor of $(1.05)^{2}$ ) leads to nominal ultimate wind loads with considerably shorter mean recurrence intervals than is the case for extratropical regions. To these mean recurrence intervals there correspond in most cases probabilities of exceedance of the nominal ultimate wind load on the order of ten percent during a 50 year lifetime of a structure. According to our results, an increase in the wind load factor would therefore be appropriate for structures subject to hurricane winds.

Acknowledgments: This work was completed during the author's tenure in the NIST/NRC Postdoctoral Research Associateship Program at NIST. Partial support by the NATO Scientific Affairs Division is also acknowledged with thanks. The author would like to thank Emil Simiu, who served as research advisor, for his suggestions and comments on this work. His participation in this project was partially supported by the National Science Foundation (Grant No. CMS-9411642). Also, the author would like to thank Alan Heckert of NIST for his assistance with the data sets and programs used in this study.

\section{References}

[1] American Society of Civil Engineers. ASCE Standard 7-93. New York, 1993.

[2] American Society of Civil Engineers. ASCE Standard 7-95. New York, 1995.

[3] M. E. Batts, M. R. Cordes, L. R. Russell, J. R. Shaver, and E. Simiu. Hurricane wind speeds in the United States. J. Struct. Div. ASCE, 100:2001-2015, 1980.

[4] E. Castillo. Extreme Value Theory in Engineering. Academic Press, New York, 1988.

[5] L. de Haan. Extreme value statistics. In J. Galambos, J. Lechner, and E. Simiu, editors, Extreme Value Theory and Applications. Kluwer Academic Publishers, Dordrecht and Boston, 1994. Vol. 1.

[6] B. Ellingwood et al. Development of a probability-based load criterion for American National Standard A58. NBS Special Publication 577, National Bureau of Standards (U.S.), Washington, DC, 1980.

[7] L. J. Shapiro. The atmospheric boundary layer flow under a translating hurricane. $J$. Atmos. Sci., 40:1984-1998, 1983.

[8] E. Simiu. Estimation of extreme wind loads. In Davenport Sixtieth Birth Anniversary Volume, pages 109-123. International Association for Wind Engineering, 1995. Ninth International Conference on Wind Engineering.

[9] E. Simiu and N. A. Heckert. Extreme wind distribution tails: A "peaks over threshold" approach. NIST Building Science Series 174, National Institute of Standards and Technology, Gaithersburg, MD, 1995. 
[10] E. Simiu, N. A. Heckert, and T. M. Whalen. Estimates of hurricane wind speeds by the "peaks over threshold" method. NIST Technical Note 1416, National Institute of Standards and Technology, Gaithersburg, MD, Feb. 1996.

[11] E. Simiu and R. H. Scanlan. Wind Effects on Structures. Wiley-Interscience, third edition, 1996.

[12] P. J. Vickery and L. A. Twisdale. Prediction of hurricane windspeeds in the U.S. J. Struct. Eng., 121:691-699, 1995. 


\title{
A Estimates of wind load factors versus threshold for locations in hurricane-prone regions
}

\author{
Legend ( $L \_R, R$ in years)

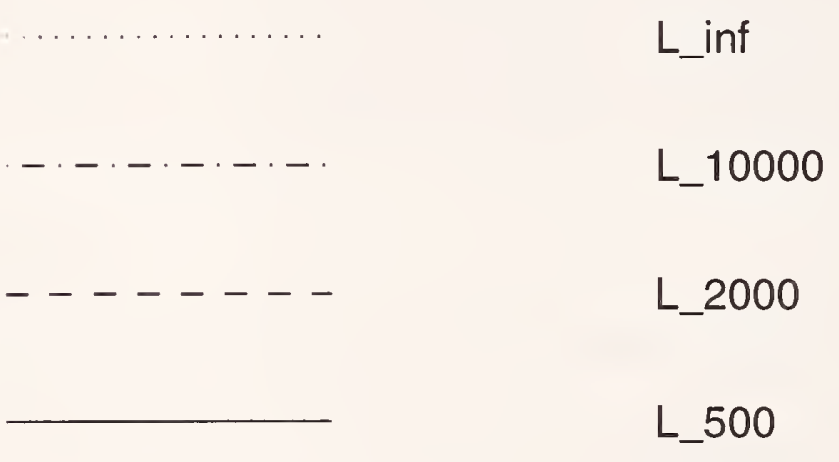 \\ ASCE Standard load factor
}



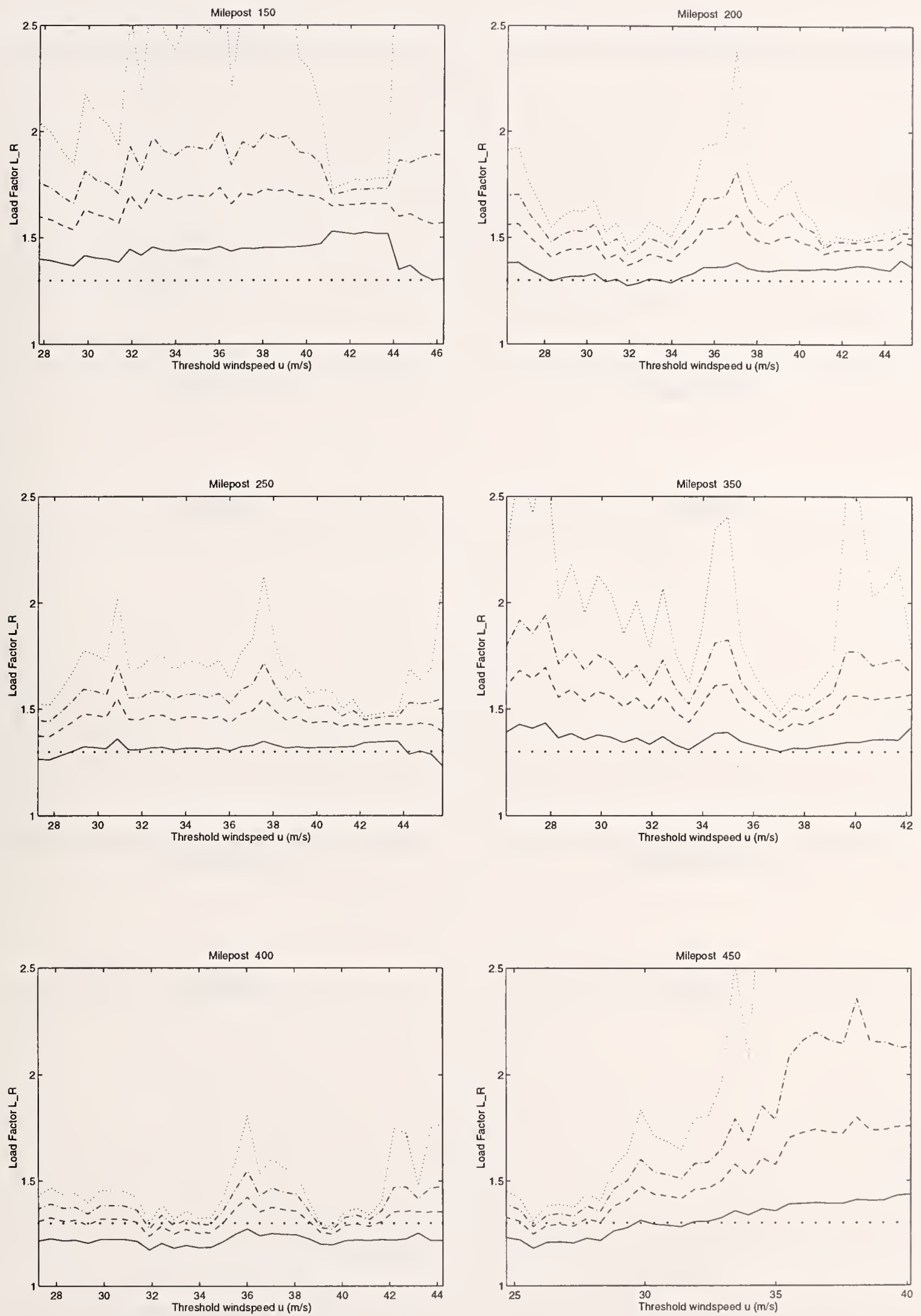

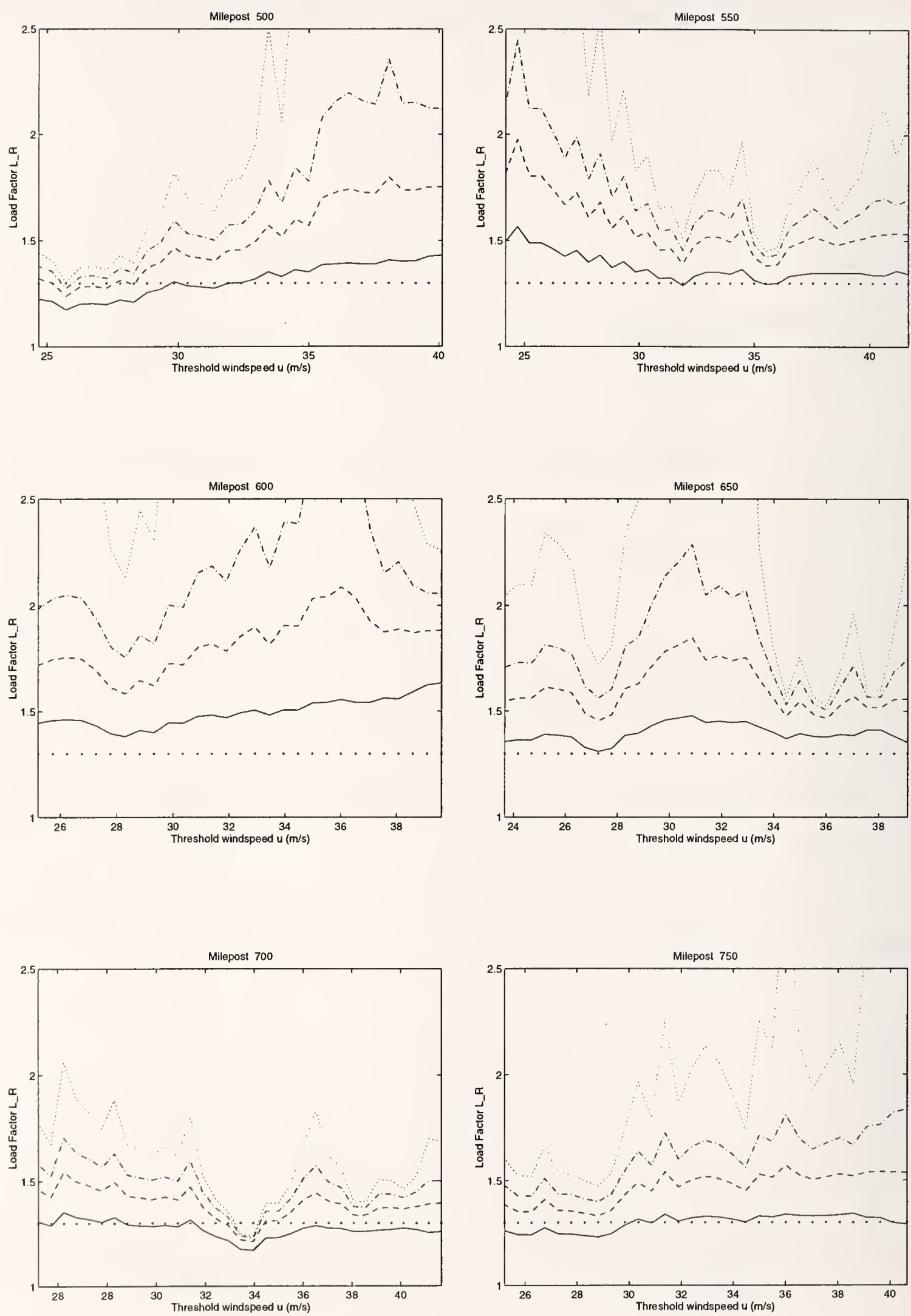

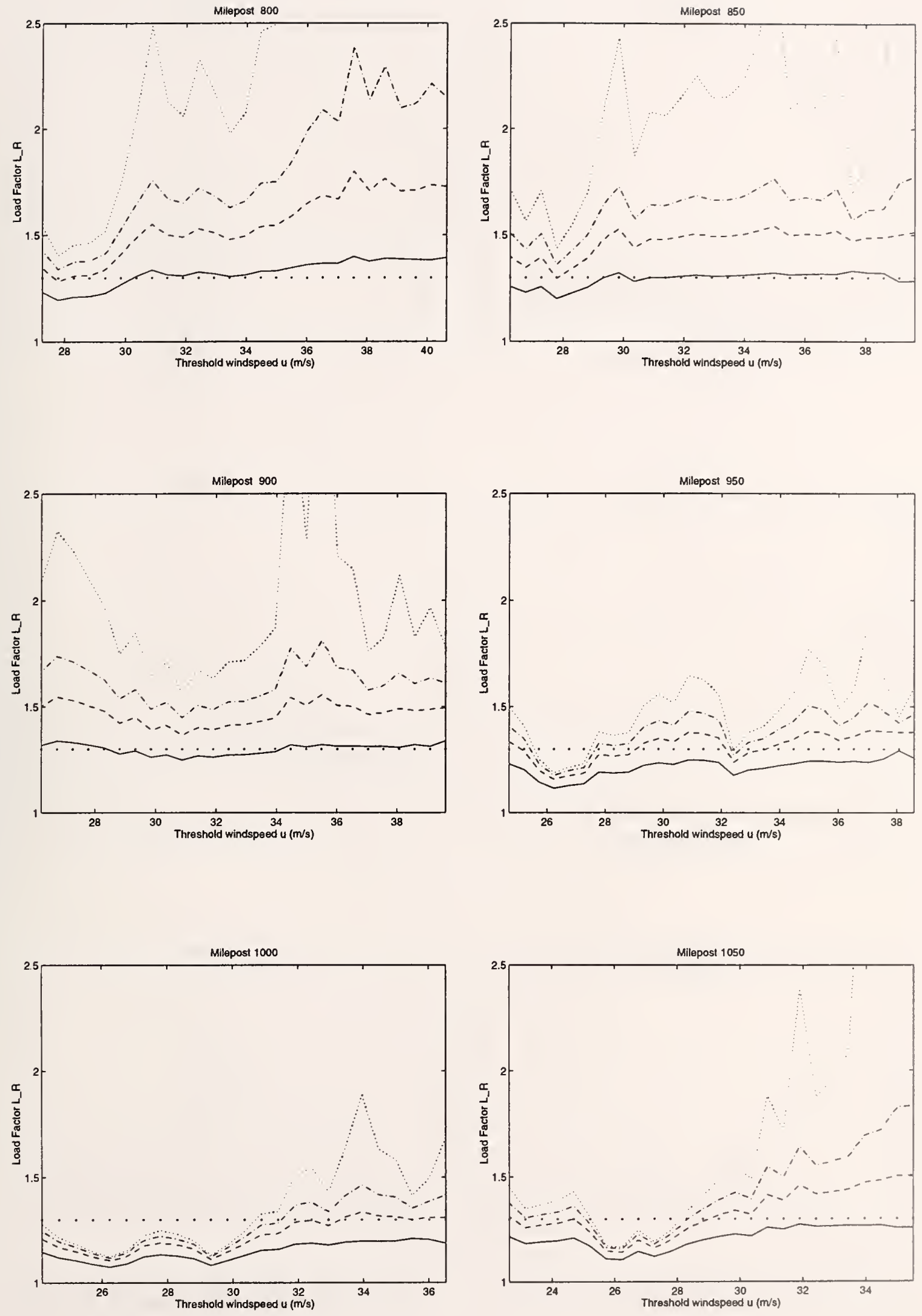

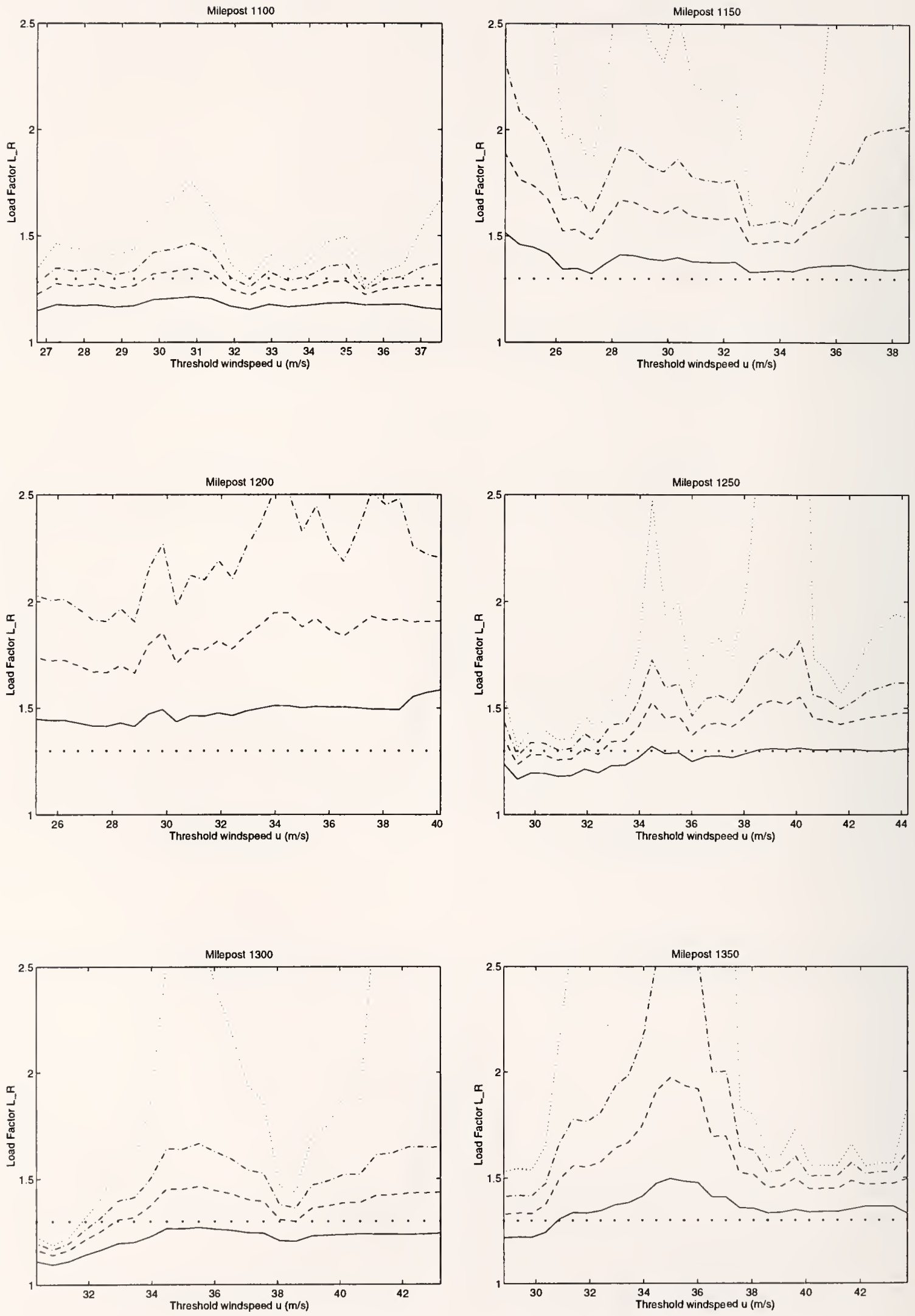

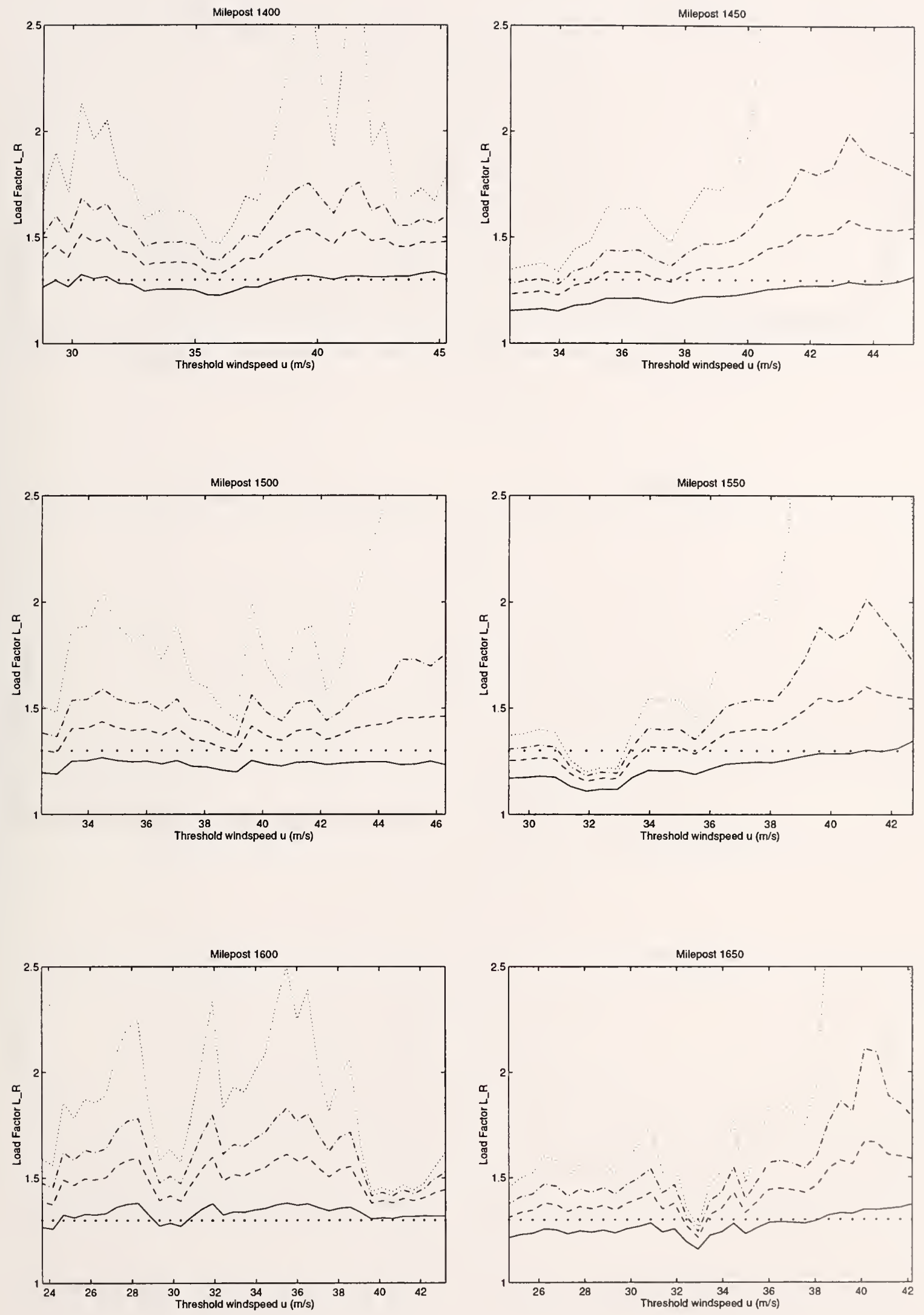

14 

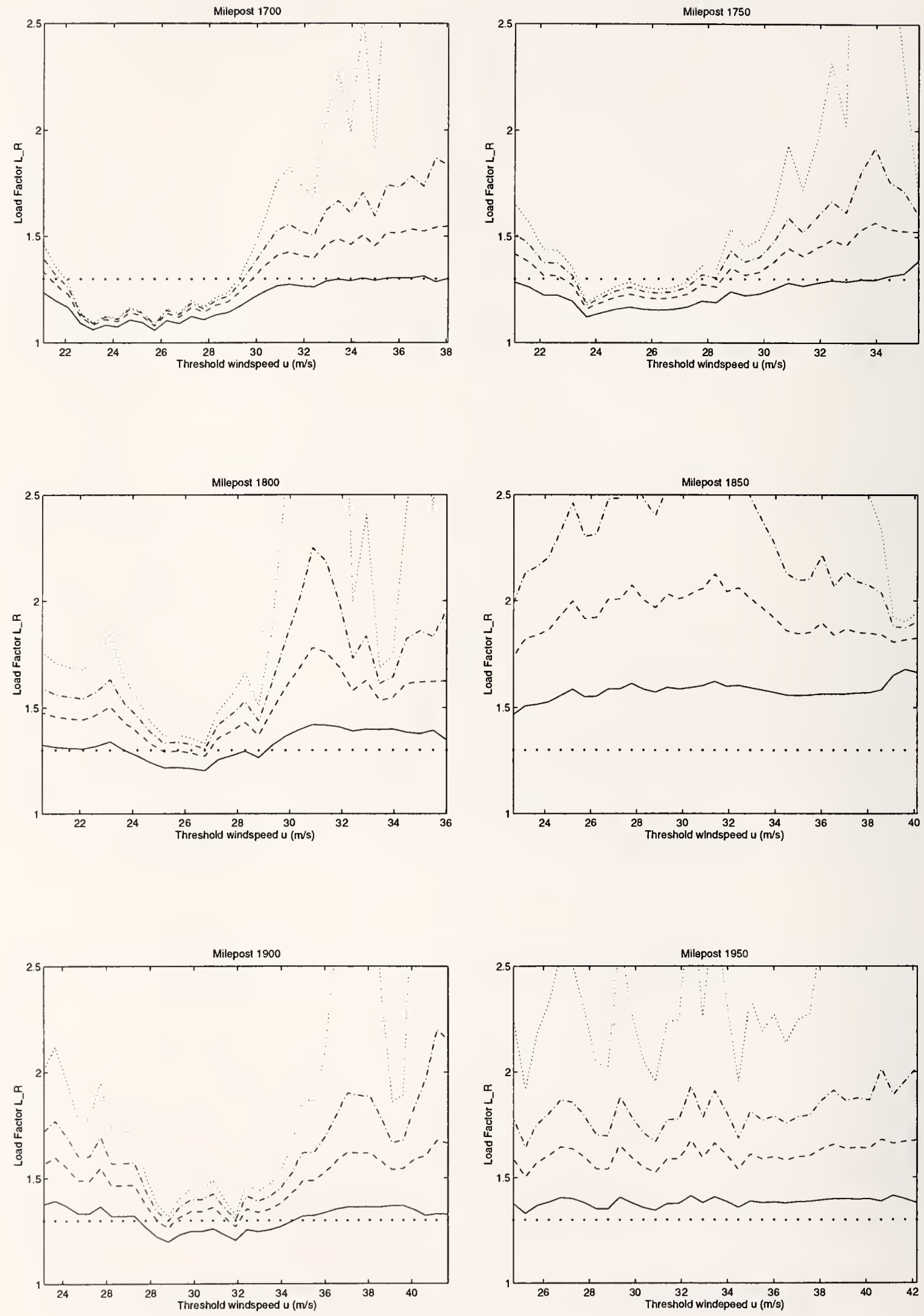

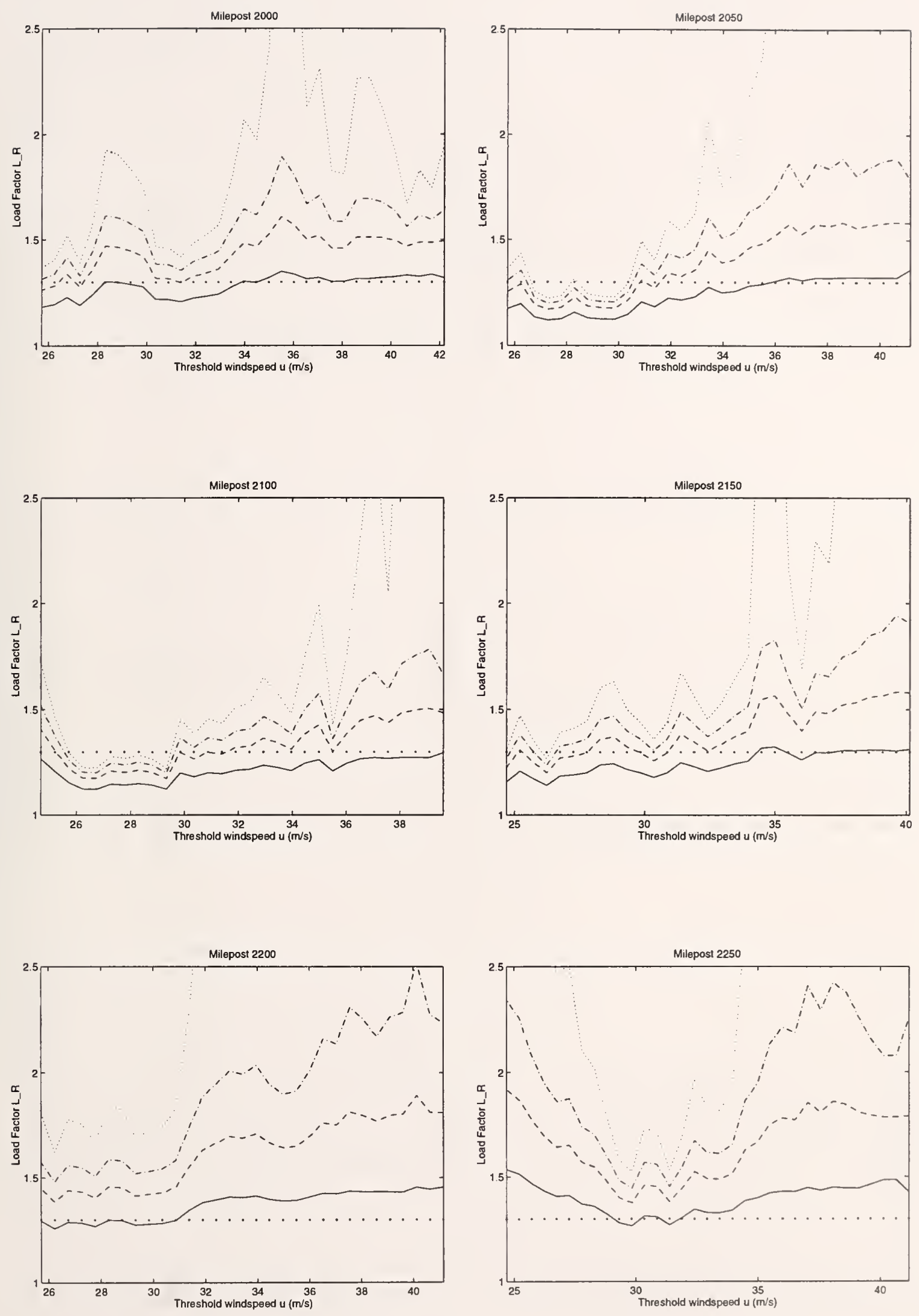

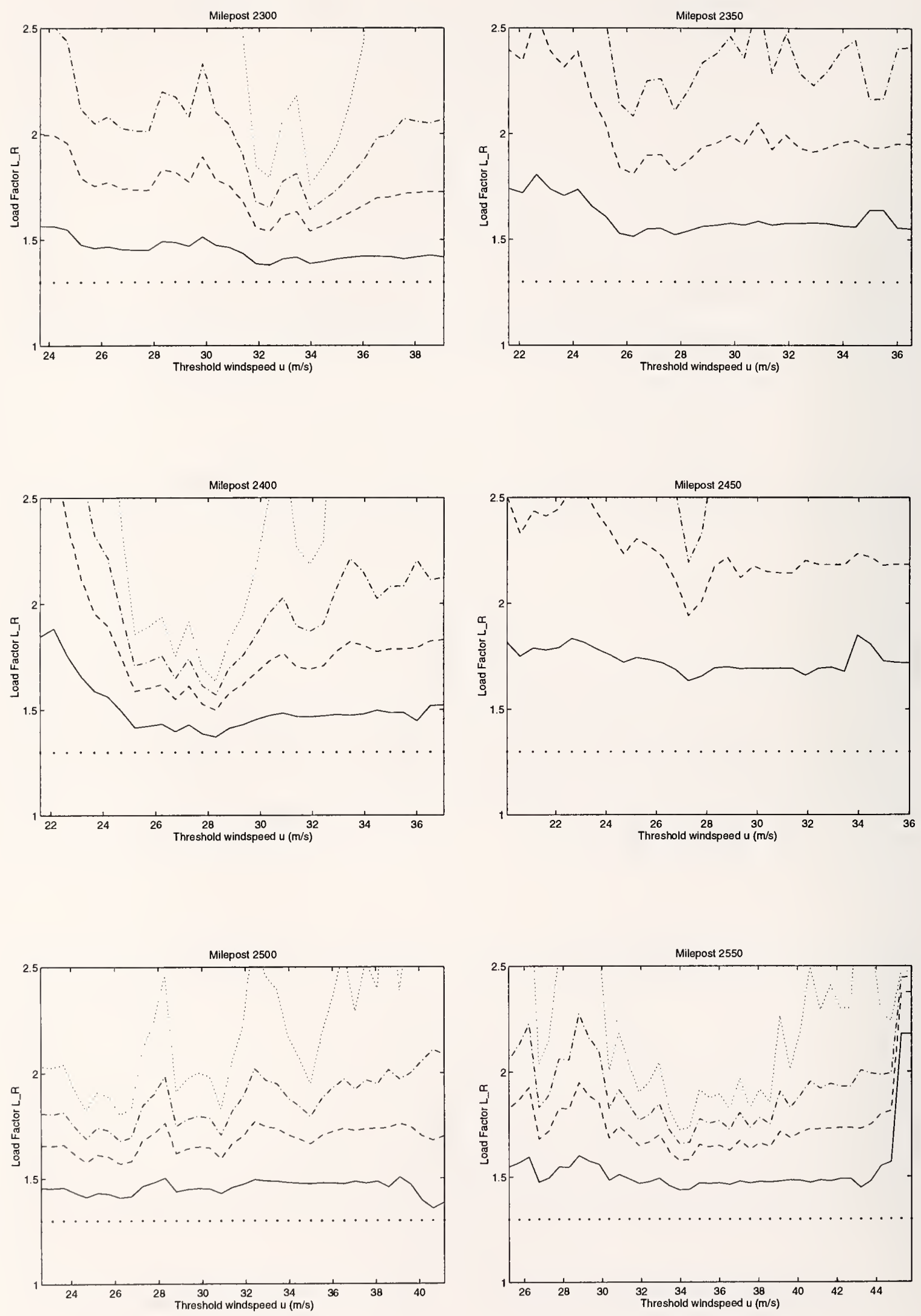

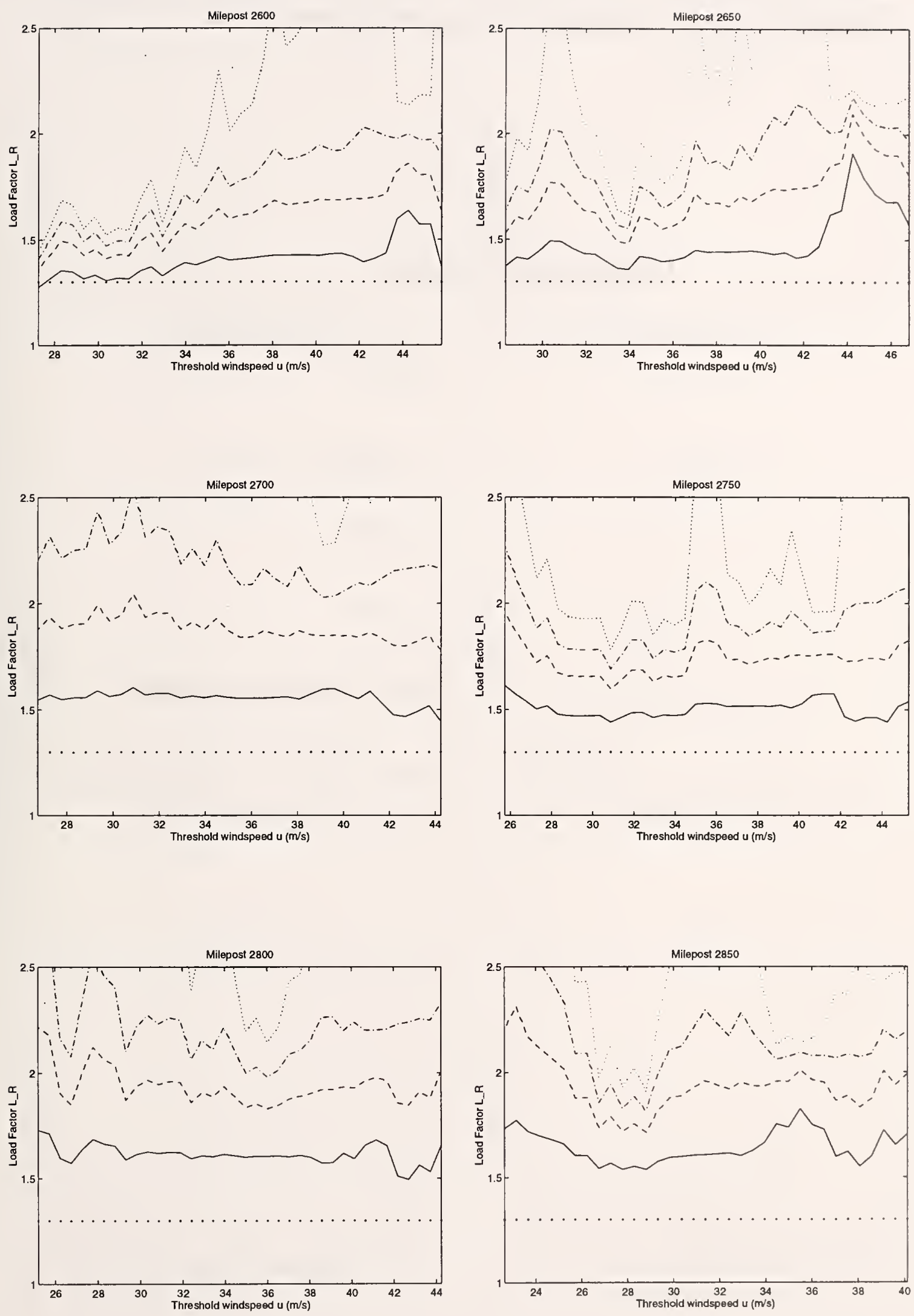
B Estimates of wind load factors versus threshold for locations in extratropical regions

Legend ( $L \_R, R$ in years)

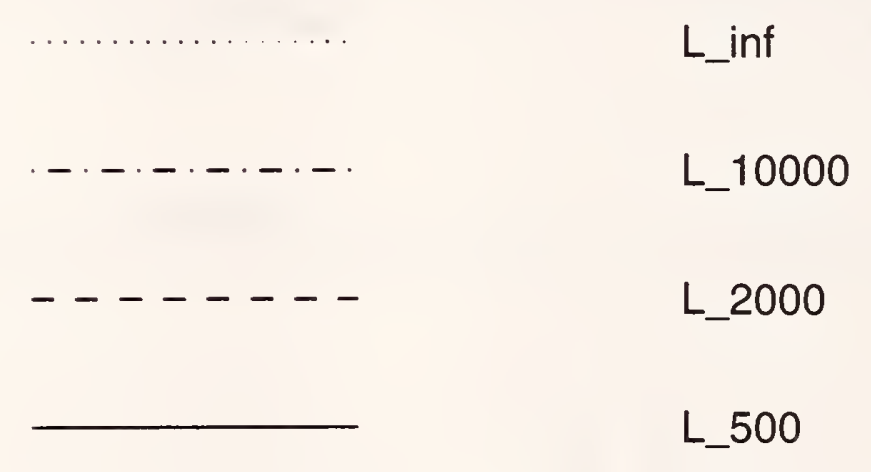

ASCE Standard load factor 

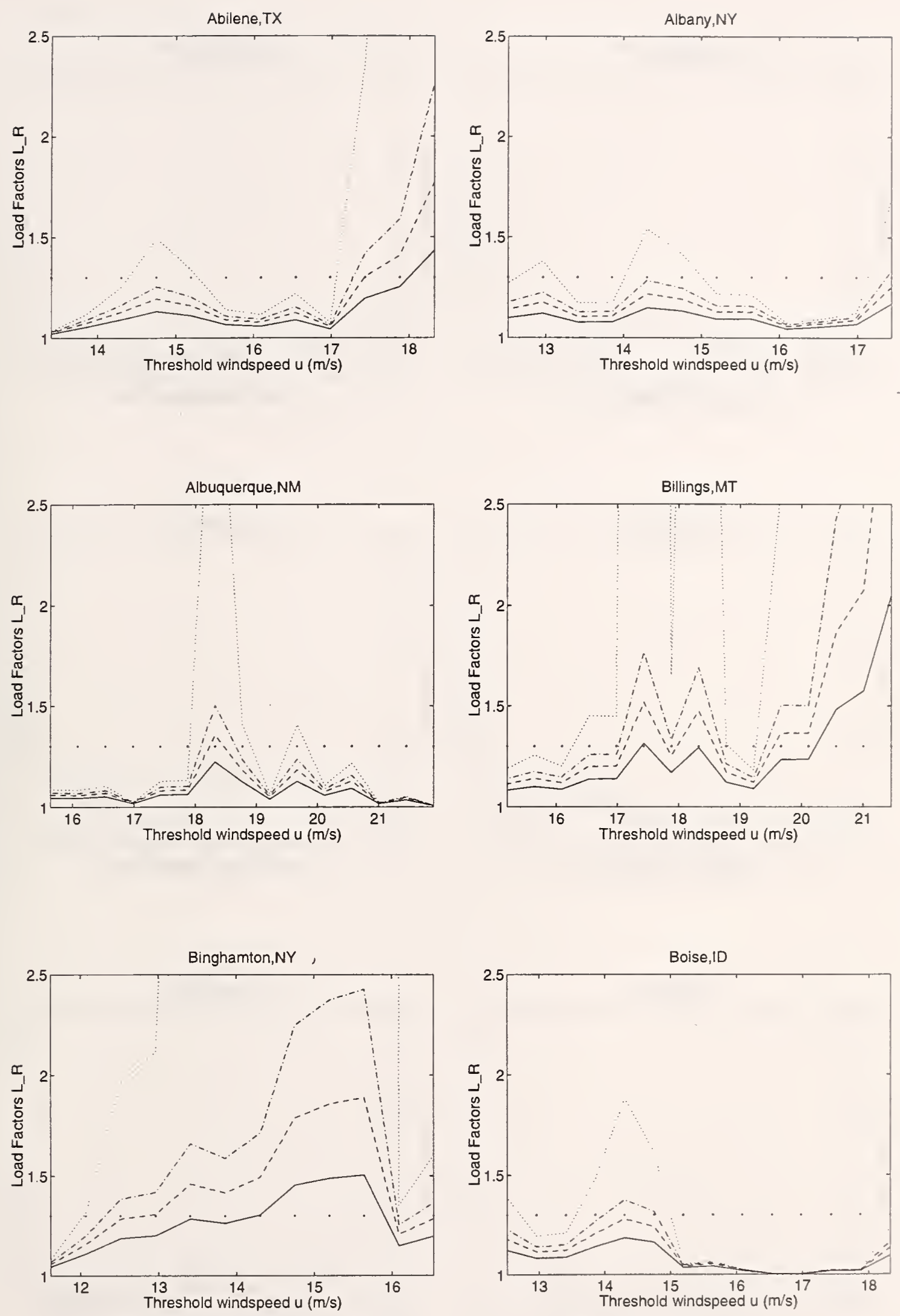

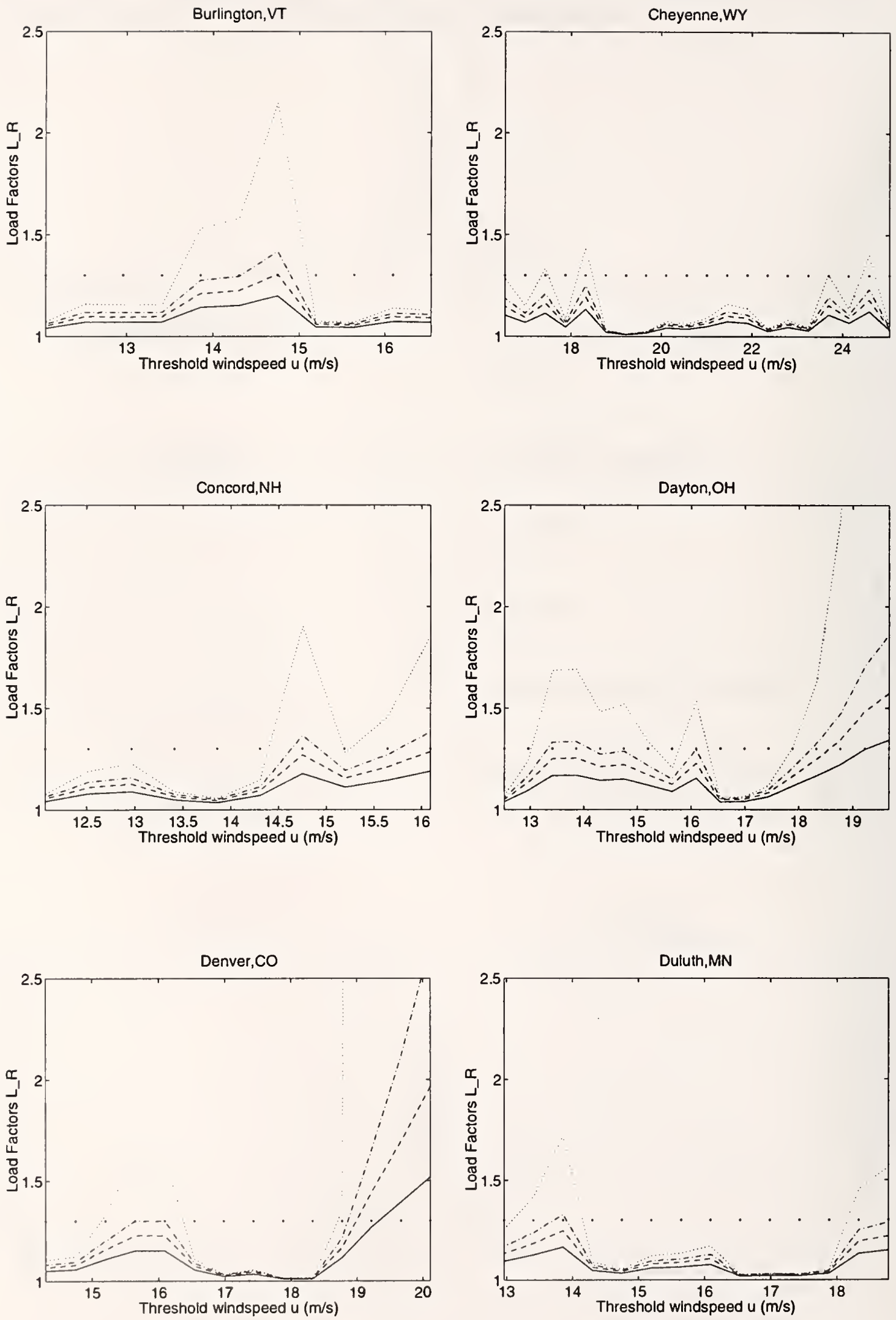

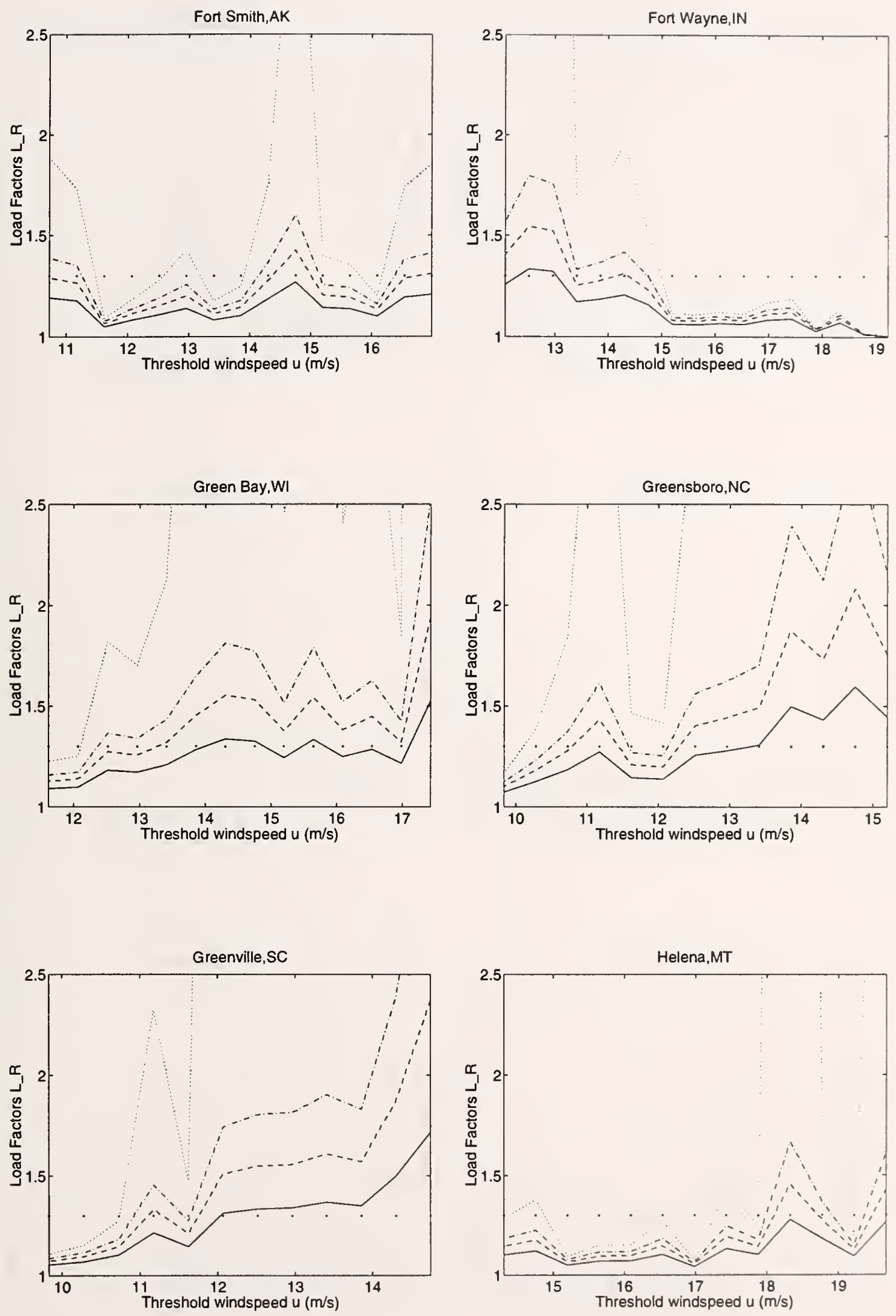

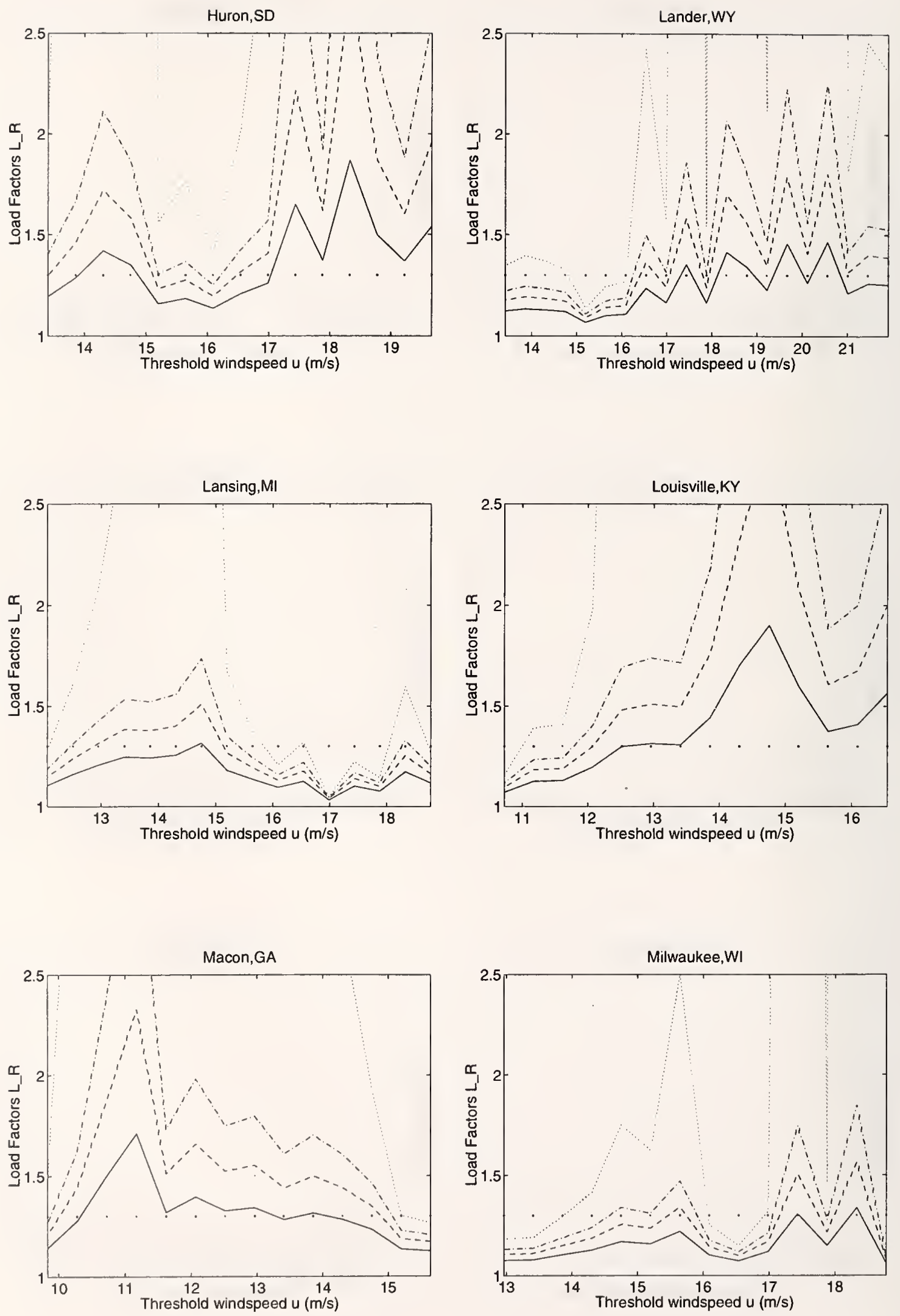

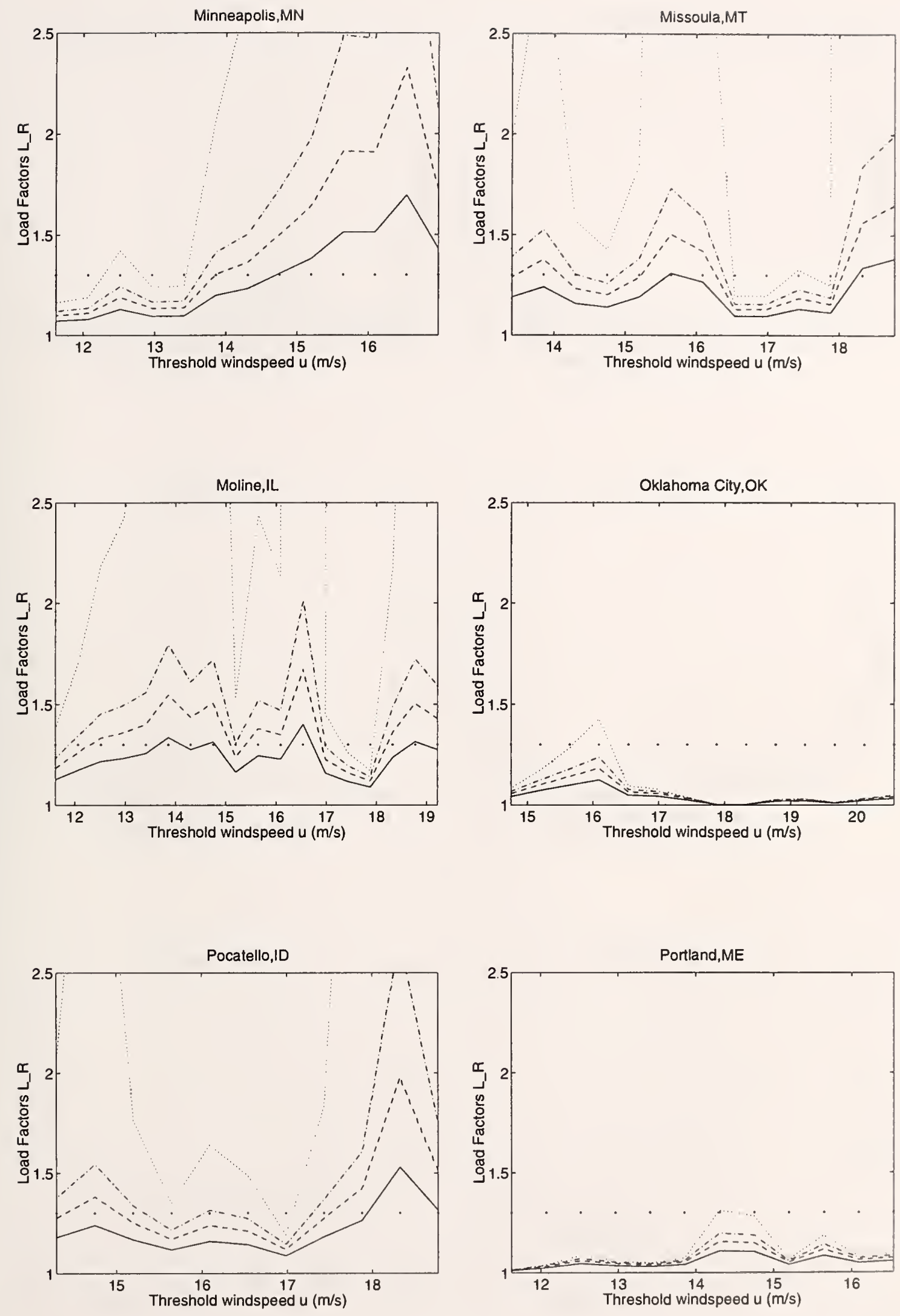

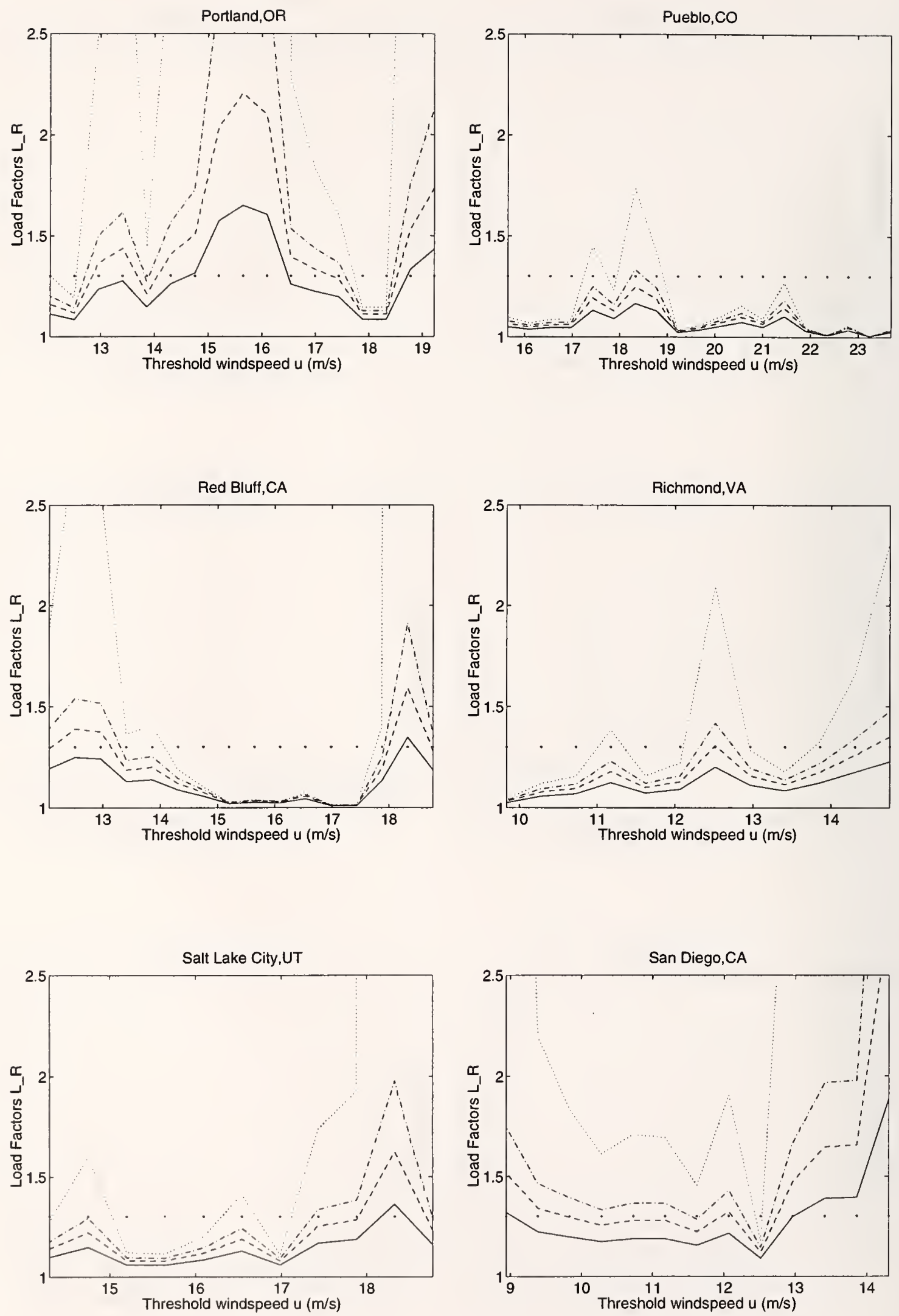

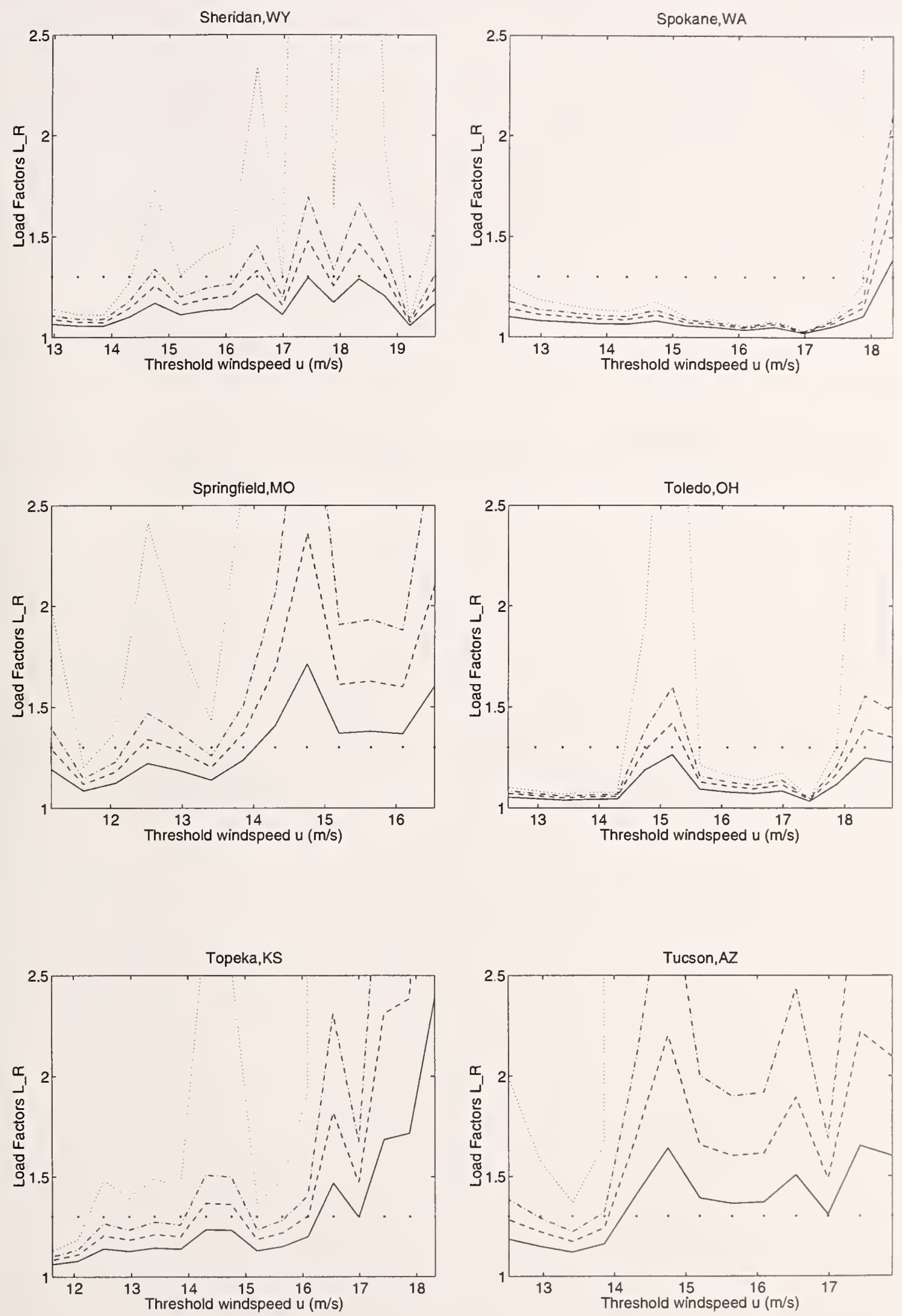

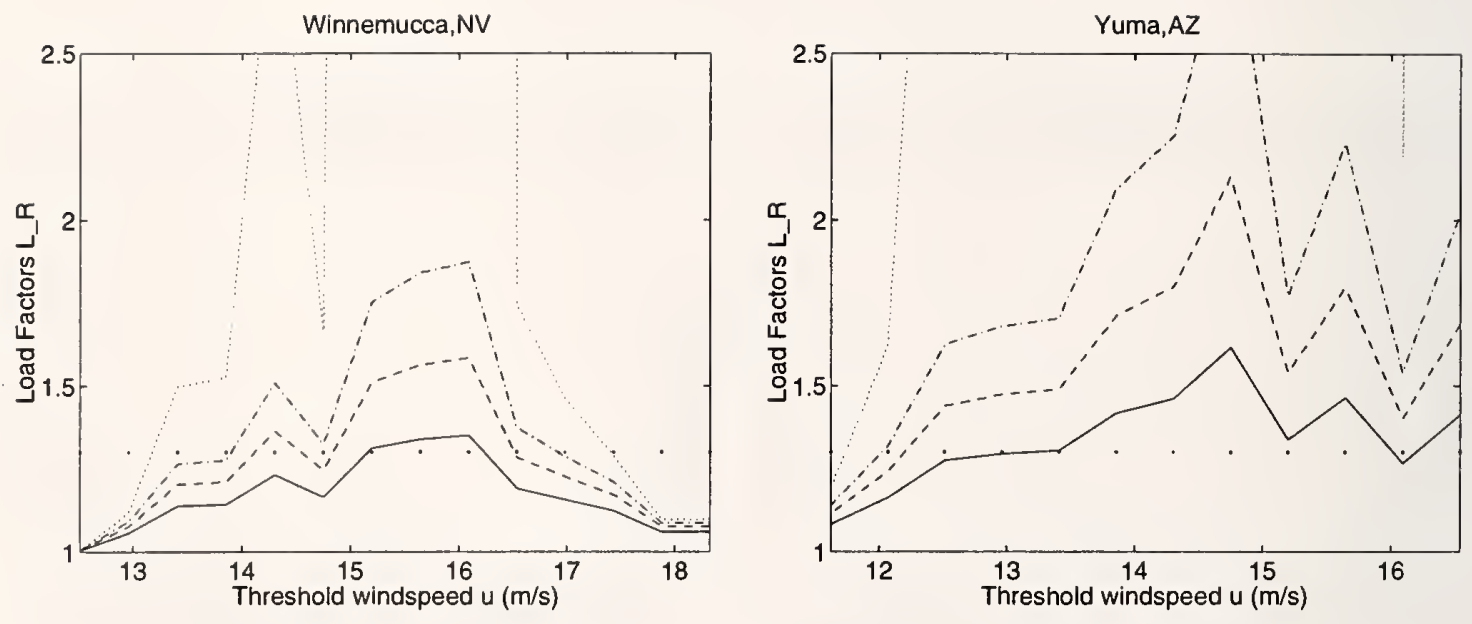




\section{Periodical}

Journal of Research of the National Institute of Standards and Technology-Reports NIST research and development in those disciplines of the physical and engineering sciences in which the Institute is active. These include physics, chemistry, engineering, mathematics, and computer sciences. Papers cover a broad range of subjects, with major emphasis on measurement methodology and the basic technology underlying standardization. Also included from time to time are survey articles on topics closely related to the Institute's technical and scientific programs. Issued six times a year.

\section{Nonperiodicals}

Monographs-Major contributions to the technical literature on various subjects related to the Institute's scientific and technical activities.

Handbooks-Recommended codes of engineering and industrial practice (including safety codes) developed in cooperation with interested industries, professional organizations, and regulatory bodies.

Special Publications - Include proceedings of conferences sponsored by NIST, NIST annual reports, and other special publications appropriate to this grouping such as wall charts, pocket cards, and bibliographies.

National Standard Reference Data Series-Provides quantitative data on the physical and chemical properties of materials, compiled from the world's literature and critically evaluated. Developed under a worldwide program coordinated by NIST under the authority of the National Standard Data Act (Public Law 90-396). NOTE: The Journal of Physical and Chemical Reference Data (JPCRD) is published bimonthly for NIST by the American Chemical Society (ACS) and the American Institute of Physics (AIP). Subscriptions, reprints, and supplements are available from ACS, 1155 Sixteenth St., NW, Washington, DC 20056.

Building Science Series-Disseminates technical information developed at the Institute on building materials, components, systems, and whole structures. The series presents research results, test methods, and performance criteria related to the structural and environmental functions and the durability and safety characteristics of building elements and systems.

Technical Notes-Studies or reports which are complete in themselves but restrictive in their treatment of a subject. Analogous to monographs but not so comprehensive in scope or definitive in treatment of the subject area. Often serve as a vehicle for final reports of work performed at NIST under the sponsorship of other government agencies.

Voluntary Product Standards-Developed under procedures published by the Department of Commerce in Part 10, Title 15, of the Code of Federal Regulations. The standards establish nationally recognized requirements for products, and provide all concerned interests with a basis for common understanding of the characteristics of the products. NIST administers this program in support of the efforts of private-scctor standardizing organizations.

Order the following NIST publications-FIPS and NISTIRs - from the National Technical Information Service, Springfield, VA 22161.

Federal Information Processing Standards Publications (FIPS PUB)—Publications in this serics collectively constitute the Federal Information Processing Standards Register. The Register serves as the official source of information in the Federal Government regarding standards issued by NIST pursuant to the Federal Property and Administrative Services Act of 1949 as amended. Public Law 89-306 (79 Stat. 1127), and as implemented by Executive Order 11717 (38 FR 12315, dated May 11, 1973) and Part 6 of Title 15 CFR (Code of Federal Regulations).

NIST Interagency Reports (NISTIR)-A special series of interim or final reports on work performed by NIST for outside sponsors (both government and nongovernment). In general, initial distribution is handled by the sponsor; public distribution is by the National Technical Information Service, Springficld, VA 22161. in paper copy or microfiche form. 


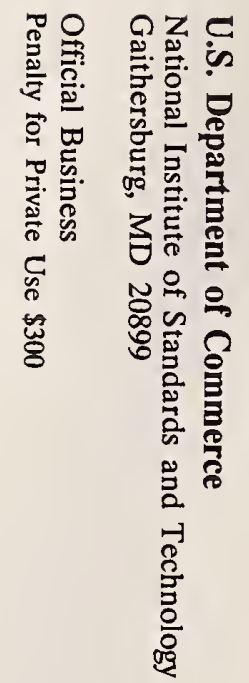

